American Journal of Pharmaceutical Education 2019; 83 (8) Article 7103.

\title{
RESEARCH
}

\section{Exploring Undergraduate Pharmacy Student Experiences of Learning Human Anatomy Using Cadaveric Specimens}

\author{
Adam Rathbone, PhD, Hamde Nazar, PhD, MPharm, Jonathan Harburn, PhD, Adam Todd, PhD, MPharm, \\ Andrew K. Husband, DProf, MSc \\ School of Pharmacy, Newcastle University, Newcastle-upon-Tyne, United Kingdom \\ Submitted April 6, 2018; accepted August 22, 2018; published October 2019.
}

\begin{abstract}
Objective. To gain insights into pharmacy students' experiences in learning human anatomy using qualitative interviews and thematic analysis.

Methods. Participants included Master of Pharmacy students at the end of their first year or the beginning of their second year. The study used a transcendental phenomenological design. Data were collected using semi-structured individual interviews that were recorded and transcribed verbatim. Thematic analysis was used to identify structural and textural components of participants' experiences using data management software.

Results. Sixteen participants were recruited and interviewed. Students described developing an understanding of anatomy that differed from their previous experiences, focusing on variation in anatomical structures between patients, and developing professional attributes such as empathy and respect. Students described haptic learning that acted as a hook on which to anchor additional learning from textbooks and lectures. Finally, students perceived the experience as valuable to their future careers as caring professionals.

Conclusion. The results of this qualitative study demonstrate that the value of teaching anatomy to undergraduate students goes beyond developing a broad knowledge of anatomical structures, but also engages a deeper conceptual appreciation of professionalism, thereby inducting them into a community of professional practice.
\end{abstract}

Keywords: anatomy, pharmacy, education, professionalism, qualitative interviews

\section{INTRODUCTION}

The role of teaching anatomy in the undergraduate education of health professionals has a long and distinguished history. From the start of the $20^{\text {th }}$ century, the preclinical education of medical students consisted almost entirely of learning anatomy, with anatomy occupying between 500 and 1200 hours of direct instruction time, depending on the specific institution. ${ }^{1}$ This approach continued well into the mid-1930s when calls for greater integration of science and clinical practice stimulated a reduction in anatomy teaching hours. This reduction has caused some researchers to suggest that the depth of anatomical knowledge among today's medical graduates is suboptimal. ${ }^{2}$ Unrelenting debate surrounds the format of delivery for the remaining anatomy instruction time, with dissection-led programs and problem-based teaching courses presenting the two extremes of a traditionalist vs modernist educational continuum. ${ }^{3}$

Corresponding Author: Adam Rathbone, School of Pharmacy, Newcastle University, King George VI Bldg., King's Rd., Newcastle-upon-Tyne, United Kingdom. Tel: 07904220720. E-mail: Adam.rathbone@newcastle.ac.uk
Anatomy teaching within undergraduate pharmacy is often undertaken as part of preprofessional education programs or integrated within physiology teaching. ${ }^{4}$ The General Pharmaceutical Council, the regulator of the pharmacy profession in the United Kingdom, does not specifically detail anatomy within their outcome-based educational standards. ${ }^{5}$ While this arguably generates greater flexibility and heterogeneity in pharmacy education as a consequence, there are few UK programs that include specific practical anatomy courses within the curriculum of the Master of Pharmacy (MPharm) program. Despite this, recent evidence has identified that pharmacists are increasingly involved in "body work," a term used in medical sociology that posits the body as an object of labor and which has been used recently to describe the inclusion of the body in pharmacists everyday work, such as during clinical assessment and clinical decisionmaking. ${ }^{6}$ In many instances, the skills pharmacists use when working with patient bodies are predicated on a knowledge of anatomy, ie, the location of systems and organs within the patient to identify, monitor, and treat diseases using pharmacotherapy. Pharmacy degree programs must 


\section{American Journal of Pharmaceutical Education 2019; 83 (8) Article 7103.}

respond to the realities of practice, as pharmacists become increasingly involved in monitoring patients' use and physiological responses to it.

In October 2013, the first students were recruited to a new anatomy course within an MPharm program. ${ }^{7}$ The program takes an integrated approach to teaching that is anchored to clinical cases, incorporating science and practice within problem-based teaching. Included within the first semester is a bespoke practical anatomy course where first-year students, through a series of sessions, are supported by lectures to explore cadaveric specimens, including whole cadavers and prosections. These sessions are designed around the 11 anatomical systems and are aimed at providing fundamental knowledge in the context of pharmaceutical sciences, which will support much of the physiological and pharmaceutical material that follows in the latter years of the MPharm program. The importance of a solid understanding of anatomy should not be understated: a deep learning approach to clinical skills, pathophysiology and therapeutics is predicated upon a thorough understanding of the underlying structures of the human body.

Little is known about pharmacy students' experiences of anatomy teaching, what they learn and how they learn anatomy. We wanted to gain a better understanding of how students experience the sights, smells, and emotions of practical anatomy sessions and whether they develop a conceptual appreciation of the anatomy of the body as a whole and of individual organs therein. ${ }^{3}$ This is important to understand as pharmaceutical education increasingly focuses on clinical pharmacy practice, whereby the bodies that pharmaceuticals are developed to influence and used on are drawn into the foreground of pharmacy practice. ${ }^{6}$ The aim of this study was therefore to explore what was learned and how it was learned to inform the process of refinement of the content of the course in the future.

\section{METHODS}

The methods for this study were underpinned by a transcendental phenomenological approach. The philosophical background of this perspective argues that reality is constructed from subjective consciousness interpreting the objective world as a lived experience. Phenomenology offered the most appropriate theoretical approach as this study sought to explore the nature of students' lived experiences of a program of teaching and how they subjectively interacted with an objective teaching platform. A phenomenological framework also facilitates the identification of previously held beliefs that enable researchers to identify, reflect on, and take account of their own role within the data collection and analysis process. ${ }^{8,9}$ As part of this approach, researchers are encouraged to reflect personally and as a group to identify their assumptions, biases, and previously held beliefs in a process known as epcohé, to improve transparency of qualitative research.

Students who had completed the anatomy course in the same academic year and were at the end of their first year or the start of their second year of the MPharm program were invited to take part in the study. A convenience sample was used as a pragmatic approach to recruiting a range of students. Participants were recruited via an emailed invitation, which included a participant information leaflet and a consent form and was circulated to the entire cohort. Informed written consent was obtained from each participant prior to his or her involvement in the study. Participants were assured that their identity would remain confidential and were given a unique participant identification number. Recruitment took place until theoretical data saturation was reached (ie, when no new ideas or themes were emerging from the interviews), as determined by three researchers. ${ }^{9}$

In-depth, semi-structured individual interviews were conducted and guided by an interview schedule that was based on the literature and included follow-up questions to probe each participant's experiences in their anatomy teaching. ${ }^{9}$ Interviews were conducted at the university at times and places convenient for the participants. All interviews were conducted in English, lasted from 30 to 40 minutes, and were in an environment conducive to obtaining good quality data, ie, a safe and quiet environment, with only the interviewer and participant present. Interviews were audio recorded and transcribed verbatim. Transcripts were quality checked against the recordings for accuracy.

Data were analysed using inductive thematic analysis to identify major themes within the data. Transcripts were read repeatedly to identify codes or nodes that described data items. Codes were interrogated across the data and clustered to develop the major themes through triangulation by three authors, with disagreements among the authors resolved through discussion and consensus. Individual themes were considered in the context of all transcripts using a constant comparison approach in order to outline a detailed overview of the phenomenon. Data were analysed using NVivo (QSR, Melbourne) data management software that supported the development and maintenance of an audit trail during the analysis. ${ }^{9}$ Multiple perspectives were considered within the transcripts, including deviant cases, during themes development until agreement was reached between the research team members via discussion and consensus. ${ }^{10}$ During thematic analysis, researchers critically reflected on their coding structure, the data, and previously held beliefs identified 


\section{American Journal of Pharmaceutical Education 2019; 83 (8) Article 7103.}

in the epoche', to examine their analysis for bias and ensure codes were apparent in the data. A small selection of participants was asked to review the themes to enhance validity ${ }^{10}$; these participants reported that the themes identified by the authors were an accurate reflection of their experience. Ethical approval for this study was granted by the program board of the postgraduate certificate in academic practice at the School of Education, Durham University.

\section{RESULTS}

Sixteen students were recruited to the study and their demographics and stage of study are detailed in Table 1 (available as supplementary material via request to the corresponding author). All students recruited were in the same cohort, had completed the anatomy teaching, and were approaching the end of their first year of study (Stage 1) or had recently started their second year of study (Stage 2) at the time of the interview. Quotes are provided and were chosen for inclusion by consensus to illustrate the themes. Four themes were identified, these were: assumptions of anatomy, anatomical variation and professional care, how students learned, and future application. Themes are described in detail below with supporting quotes provided in Tables 1-4. Theme 1 describes assumptions of anatomy that included expectations about and preparations for the anatomy laboratory (Table 1). Theme 2, anatomical variation and professional care, describes what students learned, as new knowledge and skills were developed (Table 2). Theme 3, how students learned, relates to how students experienced anatomy sessions, reporting participants' cognitive and operational experiences of learning (Table 3). Finally, theme 4, future applications, describes students' reported expectations of how learning might fit in to future pharmacy practice (Table 4). Figure 1 illustrates a coding hierarchy of what was learned by students. The figure demonstrates how data were coded, with larger boxes denoting a greater presence of the code within the data. Figure 2 illustrates the parent and child codes that were used to generate themes regarding how students experienced anatomy sessions.

In theme 1, assumptions of anatomy, participants compared their experiences of anatomy within the MPharm program to previous learning such as A-levels or Scottish Highers, which are pre-university pre-requisite qualifications in the United Kingdom, as well as to voluntary and paid work experiences. Some students based their assumptions about cadaveric tissue on previous exposure to dead people through television and films. Previous knowledge about anatomy was described as superficial in comparison to what was learned during anatomy sessions, with most students describing a shift that took place in their understanding of anatomy. Students reported a range of experiences involved in preparing for their first session, extending from practicing open-mindedness and studying pre-reading materials for the session, to anxiety, trying not to think about the session, and engaging in discussion with medical student peers as to how best to deal with the smell of formaldehyde. One student described their expectation of the atmosphere within the anatomy laboratory as akin to a graveyard and reported their experience of surprise at the scientific nature of the learning environment.

Theme 2, anatomical variation and professional care (see Figure 1 for coding structure of the analysis), included data that described students' learning outcomes. This theme was characterised by two major experiences. The first focused on learning about anatomical structures, for example the shape and size of various organs, as well as developing an understanding of individual patient variation in the same organs or anatomical systems, such as the heart and liver. Students also described learning how component parts "fit together" and the proximity between organs within an anatomical landscape. The second learning outcome that was interpreted related to professional

Table 1. Quotes Supporting Theme 1, Assumptions of Anatomy, Identified From Interviews With Pharmacy Students Regarding Their Experiences of Learning Human Anatomy Using Cadaveric Specimens

"I think I was a bit worried they'd be like a sort of atmosphere, a strange atmosphere, but it just seemed more normal than I expected. It's hard to explain, like I expected it to be kind of, like going to a graveyard or something" P3

"I thought about sort of what the session would be like in a sense. But I think the problem is with nowadays with some of the programmes that you see on television, it sort of warps the whole idea" P11

"My views have just changed like, they've almost switched" P1

"So what I'd say to people who advocate learning just from looking at a schematic is that actually seeing it in the flesh aids the understanding. Like for example when I was looking at different sections, the atria and ventricles of the heart, actually having someone go through and describe the motion of how it contracted was completely not how I'd imagined it at A-level, which I'd learnt from a textbook. And I guess that could be applied to many different contexts within the human body, such as muscle contraction and how the lungs work with the diaphragm, and actually that epitomised to me how learning out a textbook you get a general gist, but it's still not substitute for actually standing in front of a specimen and having someone talk you through it" P12 


\section{American Journal of Pharmaceutical Education 2019; 83 (8) Article 7103.}

Table 2. Quotes Supporting Theme 2, Anatomical Variation and Professional Care, Identified From Interviews With Pharmacy Students Regarding Their Experiences of Learning Human Anatomy Using Cadaveric Specimens

"I think a lot of the values that you kind of, a lot of the respect you have to have for the cadaver, you have to have for real patients as well. I think it's, I know one's dead and one's alive they're very similar and you can learn just as much of either of them really." P8

"I had no idea how complex the intestines were when you're actually pulling them out and this is the sigmoid colon, this is the ascending limb, and just things like that was - it's good to actually see that, because otherwise I wouldn't have known based on just a textbook picture." P11

"I mean that was another thing as well, like the understanding of those differences which can impact the dose and things like this. When you have a huge heart and we were like talking about the man that this heart had been taken from and how he was such a huge man but he wasn't, he wasn't fat or anything, he was just a big man, and therefore thinking about would his dose of drugs be identical to my dose? And of course it wouldn't and that, it kind of, there was an understanding there, because you can physically see it." P5

"The most difficult thing for me was that it is a real person at the end of the day. Like there was a session when we saw the head, and that was the hardest session for me. Just because you see the face and you know that's a person. And I did have to switch off and I still can picture that face now. But I still found that that helped, because in reality patients are going to die, you are going to see a patient death in your life if you work, especially if you work in hospital. So I found it's just helped me cope with that emotionally." P15

care. Although a variety of emotions were expressed, including awe, respect, and wonder, appreciation and "switching off" (emotion suppression) were also reported. Students experienced developing respect and empathy for the patient, reflecting on the privileged position of healthcare professionals, who have access to intimate parts of patients' lives and, in the case of working with cadaveric tissue, their deaths. Students described learning to control their emotions and learning to deal with death, which contributed to the development of their professionalism. One student reported that the experience was their first exposure to a patient in an academic setting, which appeared to highlight their approach or praxis of pharmaceutical care.

How students learned was clustered into the third theme, where students described cognitive and operational experiences of learning anatomy as either a hook or an anchor, providing visual cues to focus learning and prompt recall (see Figure 2 for coding chart). Students described experiences of haptic learning, ie, feeling and touching the specimens, which enabled them to achieve a deeper understanding of anatomical structures that was, at times, juxtaposed with learning from textbooks and lectures. The majority of students described learning through practical anatomy sessions more engaging than learning from textbooks or lectures, as they could more easily recall what they had seen and held. Some students reported surprise at the differences between textbook diagrams and the reality of human tissue. Students made reference to undertaking supplemental activities to support their learning, which included follow up reading for further detail. Students described having difficulty in sessions when cadaveric tissue more closely resembled living patients, for example when specimens were not pro-sectioned, nails were still painted, or faces were uncovered. Some students also described difficulty with learning in the dissection laboratory environment, as well as experiencing anxiety related to exposure to cadaveric tissue, which

Table 3. Quotes Supporting Theme 3, How Students Learned, Identified From Interviews With Pharmacy Students Regarding Their Experiences of Learning Human Anatomy Using Cadaveric Specimens

"I think it's just really useful because you can just remember it because you've seen it and you've felt it and you've been there, more so than just reading something from a textbook." P10

"I think [anatomy] is easier to remember, because you can remember the past experiences. Whereas sitting reading a book, you sit and remember reading a book a number of times but whether you pick anything up from reading that book you might not remember. But I would remember I held a brain, I had a brain in my hand and I won't forget that." P14

"The thing that bothered me was that they were like dead bodies. I wasn't really focusing on learning that day, I was just like, just tried to listen, tried to focus, but then I couldn't really until the second time, and that's basically what my first time was like for me. It was me absorbing this environment that's all I did." P9

"Because in a textbook it's difficult to sort of figure out where everything goes, because it is just a picture. You can't feel it, you can't see how it feels or how a cancerous tissue would feel compared to a normal one." P15 


\section{American Journal of Pharmaceutical Education 2019; 83 (8) Article 7103.}

Table 4. Quotes Supporting Theme 4, Future Application Identified From Interviews With Pharmacy Students Regarding Their Experiences of Learning Human Anatomy Using Cadaveric Specimens

"Sometimes when you're staring at a piece of paper you can get lost and lose that human connection, you forget what it's actually for and what it's actually relevant to. However, looking at a cadaver, it brings it back into that realm and it reminds you of actually what being a pharmacist necessarily means" P12

"Well it depends how involved we are like in the clinical side of things. Like as a, say you went into community pharmacy, like it wouldn't be as important as if we were in a hospital I'd say. Because having a global awareness of where everything is, like say someone's got cancer in their kidney, you know where it's close to, so you know where it might have spread to, therefore you can think about like what issues they might have." P7

"If someone presents with a problem, then you can think about why that problem would be there, rather than just remembering something that you've learned, that you treat this with that, then you can actually understand why you're doing that, because you can think about back to the anatomy of it and how the structures are related to one another." P10

"It kind of made me focus really on why this is important that I'm knowing this and things, like really the relevance it has and also the kind of impact of what the job is that we're doing. Because these are human beings and we like have the responsibility to give them the drugs that are going to make them healthy." P5

once overcome, enabled them to control their emotions more readily.

The fourth theme included students' reports of the future application of their experiences, which highlighted the value of having a good understanding of anatomy for their future practice as pharmacists. The majority of students identified jobs in hospital or clinical pharmacy as the roles most likely to benefit from their experiences in

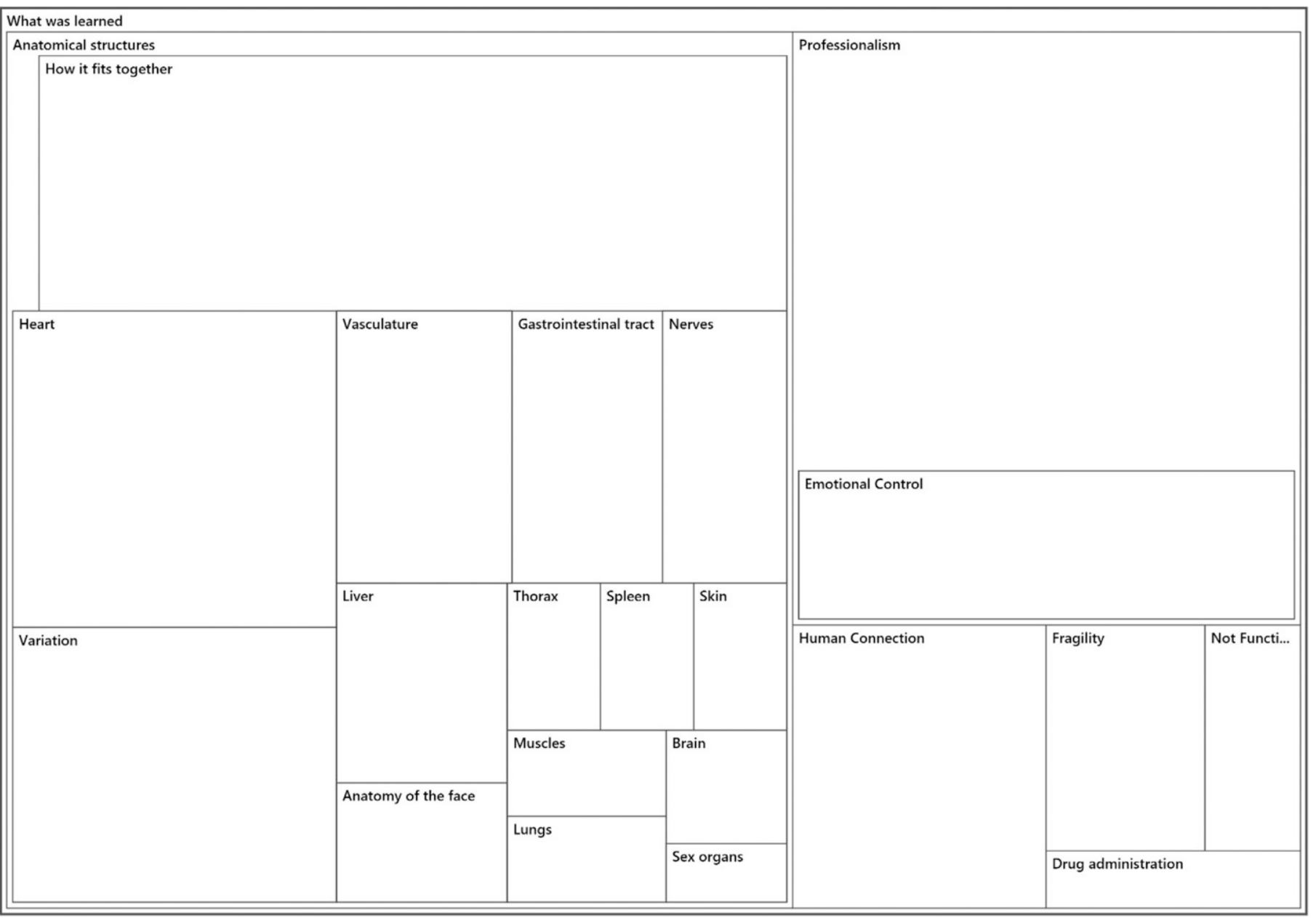

Figure 1. Coding Structure from Qualitative Analysis of "What was Learned" by Pharmacy Students Using Cadaveric Specimens to Learn Anatomy 


\section{American Journal of Pharmaceutical Education 2019; 83 (8) Article 7103.}

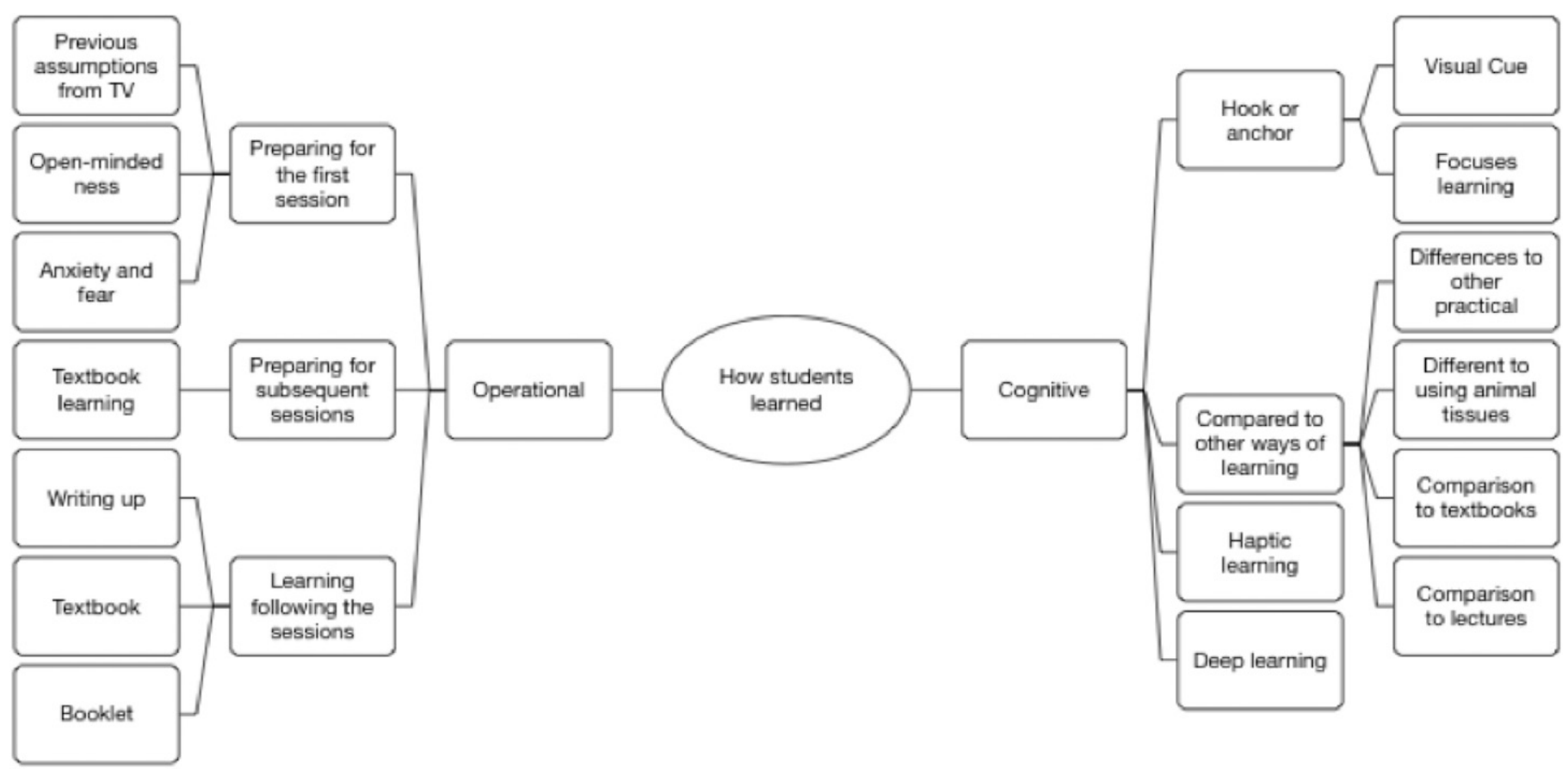

Figure 2. Coding Hierarchy of Qualitative Data to Capture How Pharmacy Students Learned Anatomy Using Cadaveric Specimens

the anatomy laboratory. However, some students reflected on the application of their knowledge to retail pharmacy and industrial roles. Students described overcoming difficulties in the dissection laboratory as informing their ability to deal with difficult situations that might arise in their future practice. Students outlined that the difficult experiences of dealing with death in anatomy had made them feel more prepared to control their emotions when faced with subsequent difficulties when practicing as pharmacists.

\section{DISCUSSION}

Students characterized their experiences of what was learned and how it was learned within two paradigms. The first described developing an understanding of the variations in anatomical structures between patients, while the second described developing attributes such as empathy, respect, and how to manage emotions in professional settings. Students described experiences of haptic learning, where hands-on experiences, sights, and smells acted as a hook on which to anchor additional learning from textbooks and lectures. Finally, students articulated the value of their learning for their future careers, particularly with regard to dealing with difficult situations in clinical practice and developing practices of patient-centred pharmaceutical care. Our study highlights a need for students to be prepared for high levels of cognitive load. ${ }^{11}$ This could be supported through reflection, such that students know themselves better, are aware of their thoughts, and can predict reactions to experiences that may be unsettling and potentially negative. Integrating reflective practice with knowledge and skill development may also prevent "ironic rebound," and so the full extent of learning may be realized more readily. ${ }^{12}$

The current literature describing anatomy teaching within pharmacy programs in the United Kingdom is scarce. Much of our existing understanding of pharmacy students' experiences of learning anatomy stems from work conducted in the United States. For example, a study by Limpach and colleagues compared student performance and perception of human anatomy teaching between a distance learning cohort and a campus-based cohort. ${ }^{13}$ This work suggests that distance learning programs can be successfully employed in pharmacy education as a way to teach human anatomy. However, in contrast to our approach in this study, the work by Limpach and colleagues used a statistical approach, quantifying success as the primary endpoint in differences in grade point averages. While these findings are a meaningful and useful method for evaluation of learning, they fail to explore the complex learning processes of hands-on anatomy teaching that may be better understood through qualitative methodologies. Future research could be conducted with pharmacy students enrolled in distance-learning programs to identify differences in the structural and textural components of the learning experience. Further research might also explore the stage at which anatomy teaching should be delivered. For example, should anatomy be taught in the 


\section{American Journal of Pharmaceutical Education 2019; 83 (8) Article 7103.}

fourth year when students' professional practices may be more established than in the first year, and what impacts would delaying instruction in anatomy have on students learning professional attributes?

Anatomy has been identified as a prerequisite for many pharmacy programs in the United States, with existing literature identifying considerable variation in prerequisite anatomy teaching. ${ }^{4}$ The inclusion of anatomy in medical undergraduate curricula and practice is well documented, although anatomy teaching in medicine in the United Kingdom has declined in recent years. ${ }^{14}$ While cadaveric dissection remains the most favoured method of anatomy teaching, only 12 out of 32 registered medical schools now offer it as their main method of teaching anatomy, favoring instead the use of technology-based teaching methods. ${ }^{14}$ This may reflect broader approaches to medical education that disassociate the patient's identity from their body, a phenomenon described as the "medical gaze," whereby bodies are increasingly measured, quantified, and abstracted from patients' identities and everyday lives. ${ }^{15}$ Removing the physical component of anatomy education arguably separates students from the reality of a patient and a patient's death. The "pharmacy gaze" describes pharmacists' perceptions of patients' bodies whereby the body is conceptualized as an abstracted, diagrammatic entity on which medicines have an effect, as opposed to a conceptualization of the body as part of the patient as a whole. ${ }^{6}$ Our findings draw on these concepts to argue that through exposure to cadaveric specimens, pharmacy students might more readily develop respect and empathy for users of pharmaceuticals, rather than a superficial, abstracted understanding of the body and its relation to medicines. Further work should consider the long-term impact of students engaging in practical anatomy sessions and the influence this has on learning physical examination techniques and consultation skills, as well as its impact on future practice.

Using human remains in education helps introduce students to death in a controlled way, alongside instruction about the process of death. ${ }^{16}$ Teaching human anatomy in this way may help start students on a journey of professional care that does not result in detachment, desensitization, and disconnection, but rather encourages patient-centred professionalism, which is required for their future as practicing pharmacists. In this way, a unique point is established whereby students may experience a dramatic change from their pre-university studies to their new, applied career pathway as a healthcare professional. For this internal change to take place, students must recognize the experience described by Festinger as dissonant, ${ }^{17}$ Mezirow as disorientating, ${ }^{18}$ and by Meyer and Land as troublesome. ${ }^{19}$ This place of transition, re- ferred to as liminal space, can be deeply emotive, sometimes taking the form of pain, fear, anxiety, or even exhilaration. ${ }^{20,21}$ Fear of the situation may invoke a state of numbness, where the learner may feel like they are suspended in time or under anesthesia, and presentation of cadavers may bring on a defensiveness in which the students shield themselves from unease through disassociation from the experience. ${ }^{22}$ An acceptance and reorganization of the sensory information can then occur at a later time, in a safer environment, inducting students into a community of professional practice. Our study sheds light on this phenomenon and suggests that pharmacy students' experience of strong emotion and "dissonance" may be part of the ritual process of professional socialization.

A limitation of a qualitative approach to research is that the findings of the study may not be generalizable and only reflect the experiences of those who took part in the research. ${ }^{9}$ However, the experience of the pharmacy students that took part in this research may be transferable to experiences of pharmacy students in similar contexts, for example, those in other areas of the United Kingdom or other countries with similar pre-professional training models. The methodology employed allowed students to provide "thick" descriptions of context, experiences, and perceptions, which improves the transferability of the findings. ${ }^{23}$ In qualitative research, it is important to reflect on the role of members of the research team. ${ }^{8}$ A drawback of this study is that the interviewers were well-known senior members of staff within the Newcastle University School of Pharmacy, and one was directly involved in teaching much of the anatomy content, which may have limited or otherwise influenced participants' responses. Future work should seek to use an independent interviewer to reduce the risk of bias. Despite these limitations, the study used a robust theoretical framework and recognized methods of data collection and analysis that improves the dependability of the results. The audit trail improved the transparency, and the analyst triangulation improved the credibility of the research.

In conclusion, this qualitative study demonstrates that teaching anatomy to undergraduate students goes beyond developing a broad knowledge of anatomical structures, and also engages a deeper conceptual appreciation of professionalism and engages the student within a professional community of practice. This work raises questions as to how anatomy teaching may be positioned within a program of study to help students to learn clinical skills, such as physical examination and consultation, and if this can be completed alongside medical student cohorts. Additional questions may be raised concerning how anatomy teaching provides a platform for other disciplinary learning, such as drug delivery. 


\section{American Journal of Pharmaceutical Education 2019; 83 (8) Article 7103.}

\section{ACKNOWLEDGMENTS}

The authors would like to thank the students for taking part in the research, members of staff that contributed to anatomy teaching for the MPharm from Durham University and Newcastle University, and those that have donated their bodies to scientific health research, education, and training.

\section{REFERENCES}

1. Drake RL, McBride JM, Lachman N, Wojciech P. Medical education in the anatomical sciences: the winds of change continue to blow. Anat Sci Educ. 2009;2:253-259.

2. Prince KJ, Scherpbier AJ, van Mameren H, Drukker J, van der Vleuten CP. Do students have sufficient knowledge of clinical anatomy? Med Educ. 2005;39:326-332.

3. Turney BW. Anatomy in a modern medical curriculum. Ann $R$ Coll Surg Engl. 2007;89:104-107.

4. Boyce E, Lawson L. Preprofessional curriculum in preparation for doctor of pharmacy education programs. Am J Pharm Educ. 2009; 73(8):Article 155.

5. General Pharmaceutical Council of Great Britain. Future Pharmacists: Standards for the Initial Education and Training of Pharmacists. London: General Pharmaceutical Council; 2011. 6. Jamie K. The pharmacy gaze: bodies in pharmacy practice. Sociol Health Illn. 2014;36(8):1141-1155.

7. Husband AK, Todd A, Fulton J. Integrating science and practince in pharmacy curricula. Am J Pharm Educ. 2014;78(3):Article 63.

8. Moustakas C. Phenomenological Research Methods. London: Sage Publications Ltd.; 1994.

9. Creswell J. Qualitative Inquiry \& Research Design: Choosing among Five Approaches. 2nd ed. CA: Sage Publications, Inc; 2007. 10. Anderson C. Presenting and evaluating qualitative research. Am J Pharm Educ. 2010;74(8):Article 141.
11. Kulig CE, Persky AM. Transition and student well-being - why we need to start the conversation. Am J Pharm Educ. 2017;81(6): Article 100.

12. Wegner DM. How to think, say, or do precisely the worst thing for any occasion. Science. July 3, 2009;325(5936):48-50.

13. Limpach AL, Bazrafshan P, Turner PD, Monaghan MS.

Effectiveness of human anatomy education for pharmacy students via the internet. Am J Pharm Educ. 2008;72(6):Article 145. 14. Ali A, Khan NZ, Konczalik W, Coughlin P, El Sayed S. The perception of anatomy teaching among UK medical students. Bulletin of the Royal College of Surgeons of England. 2015;97(9):397-400.

15. Foucault M. The Birth of the Clinic: An Archeology of Medical Perception. New York: Vintage Books; 1975.

16. Marks SC, Bertman, SL, Penny JC. Human anatomy: a foundation for education about death and dying in medicine. Clin Anat. 1997 10:118-122.

17. Festinger L. A Theory of Cognitive Dissonance. Evanston, IL: Row; 1957.

18. Mezirow J. Learning to Think Like an Adult: Core Concepts of Transformational Theory. In: Mezirow J, ed. Learning as Transformation: Critical Perspectives on a Theory in Progress. San Francisco: JosseyBass; 2000.

19. Meyer JHF, Land R. Threshold Concepts and Troublesome Knowledge: Linkages to Ways of Thinking and Practicing Within the Disciplines. In: Rust C, ed. Improving Student Learning Theory and Practice - 10 Years On. Oxford, UK: Oxford for Staff and Learning Development; 2003.

20. Boyd RD, Myers JG. Transformative education. Int J Lifelong Educ. 1998;7(4):261-284.

21. Love PG, Guthrie VL. Kegan's orders of consciousness. New Directions for Student Services. 1999;88:65-76.

22. Segal S. The existential conditions of explicitness: a Heideggerian perspective. Studies in Conditioning Educ. 1999;21(1):73-89.

23. Denzin NK, Lincoln YS. The SAGE Handbook of Qualitative Research. 3rd ed. Thousand Oaks; London: Sage; 2005. 